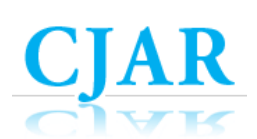

Canadian Journal of Action Research

Volume 21, Issue 2, 2021, pages 1-3

\title{
ACTION RESEARCH AND “A NOBLE AGENDA” An Editorial
}

\author{
Daniel B. Robinson \\ St. Francis-Xavier University
}

Of all the possibilities and promises of action research, its potential to attend to and effect meaningful social change is one of the most praise-worthy (Greenwood \& Levin, 2007). At least, it is to me. In my own action research-related endeavors, I have viewed action research the same way as have Reason and Bradbury (2001) - that is, as a "participatory, democratic process concerned with developing practical knowledge in the pursuit of worthwhile human purposes" (p. 1). Certainly, employing action research (particularly participatory action research) as a mechanism to promote social change offers researchers a host of opportunities to improve upon the experiences and lives of many. I have come to see these sorts of efforts and endeavors as ones aimed at attending to a sort of noble agenda. Both by way of beginning with such an orientation and inviting the genuine input and perspectives of others (oftentimes in entirely socially democratic ways), action researchers continue to positively impact the lives of individuals and groups, and the institutions and communities in which they learn, work, and live.

And so, it is with great appreciation and admiration that I introduce the authors and their works in this issue of the Canadian Journal of Action Research - works that all attend to this noble agenda. Anna Azulai, for example, suggests grounded theorists might learn from action researchers some of the ways in which research can foster meaningful and purposeful social change; she also highlights attention to social justice as a research goal and process within both constructivist grounded theory and participatory action research. The others have taken up various social change efforts, largely directed upon specific identities and/or individuals: Mehmoona Moosa-Mitha and Bruce Wallace look to improve upon the lives of Arabic speaking immigrant newcomers; Glenda L. Black looks to improve upon the abilities of teacher candidates to enable their own students to be agents of change in a rapidly changing and increasingly globally interconnected world; Amanda Eppley, Blanca GamezDjokic, and Deborah McKoy look to improve upon the lives of Black male youth; and Michael Dunn and Rona Pogrund look to better support the learning of students with visual impairments. So, though the five articles included herein all attend to differing objectives, they all share in their contributions to this noble agenda - one held by many who adopt and engage in action research. 
Anna Azulai (MacEwan University) offers a consideration of the compatibility of grounded theory and action research, particularly as it relates to methodological triangulation possibilities. Given that some employ both grounded theory and action research, Azulai's contribution offers readers a comparative review of grounded theory and action research, alongside a commentary on these methodologies' complementarities. Though the article isby Azulai's own admission-aimed at graduate students and novice researchers, all scholars whose work includes action research will find the considerations and commentaries within it to be helpful. For example, Azulai's overview of the various iterations of grounded theory (namely traditional Glaserian, Straussian, and constructivist grounded theory) provides readers with a sense of the possibilities for compatibility with action research (participatory action research, action inquiry, action learning, etc.). Certainly, one of the most important contributions here is Azulai's offerings related to methodological triangulation of grounded theory and action research.

Mehmoona Moosa-Mitha (University of Victoria) and Bruce Wallace (University of Victoria) share their lessons learned while designing a community-based participatory action research study with Arabic speaking newcomers and their various service providers. MoosaMitha and Wallace engaged refugee newcomers themselves as they set out to design and conduct a study focusing upon refugee newcomers' trauma. Within this preliminary study, Moosa-Mitha and Wallace affirm, among other things, the importance of researching refugee newcomers' trauma and ensuring efforts are made to achieve cultural safety while engaging in that research. Lastly, Moosa-Mitha and Wallace offer three core principles for conducting community-based participatory action research: redressing power imbalances, identifying mutual benefits of research, and incorporating community knowledge in a study design.

Glenda L. Black (Nipissing University) offers a critical examination of the experiences of teacher educators and their teacher candidates as they implemented an action research assignment as a compulsory course component. Employing a case study design, Black's research investigated the challenges faced, as well the benefits experienced, by teacher educators and teacher candidates. Moreover, Black also investigated how participating in their action research projects impacted teacher candidates' professional development as reflective practitioners. Black's discussion, with a focus upon opportunities and limitations related to these sorts of action research exercises, attends to four key themes: resistance, reflection, recognition, and recommendations. With this discussion, Black provides some implications for teacher preparation practice and research.

Amanda Eppley (University of California-Berkeley Center for Cities \& Schools), Blanca Gamez-Djokic (University of California-Berkeley), and Deborah McKoy (Institute of Urban and Regional Development) provide an analysis of the implementation of a communitybased action research project (Youth, Research and Plan [YRP]) with Black male youth. Using a case study approach, Gamez-Djokic et al. examine how YRP was an essential exercise in the development of various Communities of Practice (CoP) that support Black male youth's academic endeavors and civic agency. Engaging with five classes of students within a unique educational program called 'Black Manhood Achievement', Gamez-Djokic et al. utilized many data sources to focus upon Black male youth's CoP-specifically the School CoP, the College

The Canadian Journal of Action Research, Volume, 21, Issue 2 (2021), 1-3. 
CoP, and the City Planning CoP. Gamez-Djokic et al. found that the YRP project provides opportunities for $\mathrm{CoP}$ members from multiple groups and across multiple racialized identities to come together, build relationships, and co-seek solutions to shared challenges. Fittingly, Gamez-Djokic et al. offer their observed positive outcomes for Black male youth and the adult agents who work with them.

Michael Dunn (Washington State University, Vancouver) and Rona Pogrund (Texas Tech University) offer results related to their action research study in which a mnemonic strategy was introduced to students with visual impairments so that they improve upon their argumentative essay writing abilities. After students learned and applied Dunn's ARGUE mnemonic strategy (analyze, review, generate, use, express), both Dunn and Pogrund aimed to determine if students' abilities improved (in quality and content), while also seeking students' perceptions about ARGUE. Most students (80\%) did indeed demonstrate progress in both quality and content, and many found ARGUE to be helpful, even recognizing how it might be applied across parallel contexts. With these results, Dunn and Pogrund offer ARGUE as a pedagogical consideration for those who teach students with visual impairments and/or students learning English language arts.

Together, these authors make this issue of the Canadian Journal of Action Research one in which each contribution is especially relevant to other action researchers who share a commitment to promoting positive social change.

\section{REFERENCES}

Greenwood, D. J., \& Levin, M. (2017). Introduction to action research: Social research for social change (2nd ed.). SAGE.

Reason, P., \& Bradbury, H. (Eds.). (2001). Handbook of action research: Participative inquiry and practice. SAGE. 